\title{
Preparation and characterization of eco-friendly hybrid biocomposites from natural rubber, biocarbon, and carbon black
}

\author{
D. M. Paleri ${ }^{1}$, A. Rodriguez-Uribe ${ }^{1}$, M. Misra ${ }^{1,2}$, A. K. Mohanty ${ }^{1,2 *}$ \\ ${ }^{1}$ Bioproducts Discovery and Development Centre, Department of Plant Agriculture, Crop Science Building, University of \\ Guelph, Guelph, Ontario, N1G 2W1, Canada \\ ${ }^{2}$ School of Engineering, Thornbrough Building, University of Guelph, Guelph, Ontario, N1G 2W1, Canada
}

Received 8 June 2020; accepted in revised form 6 August 2020

\begin{abstract}
This study aims to investigate the effect of different carbonaceous fillers, carbon black (CB) biocarbon (BC), and a hybrid filler of both (BC-CB), in a natural rubber matrix. It was found that the addition of hybrid filler based on a sustainable biocarbon $(\mathrm{BC})$ and carbon black $(\mathrm{CB})$ revealed a significant effect on reducing the rolling resistance properties. Dried distillers' grain with solubles (DDGS), a co-product from corn ethanol industry pyrolyzed at $900^{\circ} \mathrm{C}$, was used to produce the biocarbon. As compared to the carbon black, the particle size of the biocarbon was larger which was reflected in the tensile strength of the biocarbon composites. This observation was correlated using swelling studies and found to be proportional to their crosslink density. The thermal characterizations showed similar transitions and degradation mechanisms in all the composites, which confirmed a comparatively similar behavior of $\mathrm{BC}$ with $\mathrm{CB}$. Moreover, these findings justify further tuning of biocarbon into nanosize and this could expand the scope in the utilization of this sustainable filler for the fabrication of various rubber products such as tires and hoses, etc.
\end{abstract}

Keywords: polymer composites, reinforcement, mechanical properties, thermal properties

\section{Introduction}

Rising energy costs, concerns over greenhouse gas emissions, and the non-renewable nature of fossil fuels have encouraged outstanding research in the conversion of biomass into biocarbon and other value-added renewable products [1]. In recent times, the introduction of biocarbon in polymer matrices has received increasing attention, and there is a growing awareness that it can provide a versatile and efficient platform for replacing petroleum-based materials such as carbon black [2-4]. The incorporation of carbon black in tires in the $20^{\text {th }}$ century resulted in a 10-fold increase in the performance of tires, and since then, carbon black has been the predominant reinforcing material for use in rubber matrices [5].
Moreover, the carbon black constitutes $30 \%$ of most rubber compounds, and hence the whole rubber industry depends on this non-renewable petro-based carbonaceous filler [6].

More than $70 \%$ of the rubber products are constituted of ingredients from petroleum, which includes synthetic rubbers and carbon black [7, 8]. Apart from the dependency on petroleum products, the carbon black is reported to cause health concerns associated with the respiratory system [9-12]. Different types of carbonaceous fillers, such as carbon black, carbon nanotubes, graphene etc. were introduced in rubber matrices for achieving better physicomechanical properties via enhanced reinforcement. Among those, carbon blacks are aggregated nanoparticles

$\overline{{ }^{*} \text { Corresponding author, e-mail: mohanty@uoguelph.ca }}$

(C) BME-PT 
and widely used as a filler in plastics and rubber materials due to their cost-effectiveness and unique properties. Specifically, the performance properties of rubber products are significantly influenced by the characteristics of carbon black, and so a smart biosubstitute is essential to balance properties and sustainability. The unique reinforcing effect of carbon black has been well explored, and attempts were made to replace it by using various cellulose derived fillers through the regeneration of nanocellulose [13] and pyrolysis [14]. Pyrolysis is the incomplete decomposition of biomass in the absence of oxygen. Depending on the requirement, a variety of carbon blacks are available, and, similarly, different varieties of biocarbon can be pyrolyzed depending on the source of biomass and pyrolysis conditions. The utilization of suitable waste biomass such as wood $[15,16]$, perennial grasses [3, 17-19], chicken feathers [20], soy hull [21], coffee chaff [22] and dried distiller's grains with solubles (DDGS) [23] with pyrolysis at optimized temperature can result in biocarbon having specific properties. Among those, supplies of DDGS in North America have enhanced significantly during the last 10 years, with quantities probably reaching more than 42 million tons per year [24]. Hence, the scope for exploring DDGS based biocarbon is considerable. The production of biocarbon from renewable feedstock is very advantageous due to the abundance, diversity, eco-friendliness, lower cost, and effective waste management strategy [23]. The characteristics of biocarbon directly depend on the type of biomass, pyrolysis temperature, residence time, feedstock size, porosity, surface chemistry etc., and those factors can be varied according to the use for energy storage, catalysis and pollutant abatement or as a reinforcing filler in polymer matrices [20]. Most of the reported work in the field of biocarbon composites are based on plastic-based matrices such as polyethylene (PE), polypropylene (PP), polyamides, etc. with various biocarbons from wood and perennial grasses [25-27].

Elastomer matrices are amorphous matrices and hence possess a huge scope for reinforcement. The most widely used reinforcing filler for elastomerbased matrices is carbon black due to its characteristic networks like morphology called 'structure' [6]. As compared to the conventional reinforcing fillers such as carbon black, the reinforcing properties of biocarbon are comparatively less due to the larger particle size and lack of unique 'structure', and hence elastomer-based matrices are very less explored for the preparation of biocarbon composites [2,5]. Jong et al. [7] studied various types of biocarbon derived from wood and coconut shells in natural rubber matrices and concluded that coconut shellbased biocarbon promoted the tensile modulus of the matrix significantly. Also, Peterson et al. [28] studied the effect of birchwood biocarbon in styrene-butadiene matrix-based composites and confirmed the enhanced tensile strength properties. Recently, Peterson and Kim studied the effect of particle size reduction on the reinforcement of the rubber matrix [29]. Moreover, Xue et al. [30] studied the effect of ball milling time on the reinforcement action of rice husk biocarbon in rubber compounds and confirmed that smaller particle size promotes reinforcement. An overall reduction of tensile strength was found with the addition of biocarbon as compared to carbon black in all the reported works. Hence, the addition of hybrid filler based on biocarbon and carbon black could provide better performance in an elastomeric matrix. The incorporation of hybrid fillers based on lignin and carbon black in rubber compounds was reported with a reduced viscoelastic loss with enhanced mechanical properties [31]. In 2006, Agarwal et al. [32] studied the effect of corn powder on NR-SBR (styrene-butadiene rubber) blend matrix and concluded that corn filler promoted lower rolling loss in passenger tire tread compounds. Also, the role of corn starch and corn stover based biocarbon was compared in carboxylated styrene-butadiene rubber, and it was reported that higher reinforcement was observed with corn starch addition [8]. As the role of DDGS or any related corn-based filler has not been explored in a natural rubber matrix, a systematic comparative study of DDGS based biocarbon and carbon black in natural rubber matrix could reveal the performance properties, and hence result in better understanding of the reinforcement mechanism.

Scrutiny of the available literature reveals that there is no work reported based on the natural rubber composites utilizing sustainable carbonized filler based on DDGS focused on dynamic mechanical properties. In this study, it is proposed to utilize biocarbon, carbon black, and the hybrid filler based on biocarbon and carbon black to explore the partial replacement of carbon black in rubber vulcanizates. 


\section{Experimental}

\subsection{Materials}

Natural Rubber (Ribbed smoked sheets-IV) was purchased from Astlett Rubber Inc. Canada. Carbon black (Continex ${ }^{\mathrm{TM}}$ N762, a semi-reinforcing black) purchased from Continental carbon, USA, and dried distillers' grains with solubles (DDGS) was kindly supplied by IGPC Ontario, Canada. Zinc oxide, stearic acid, sulfur, and tetramethyl thiuram disulfide (TMTD) were procured from Sigma Aldrich, Canada. All the rubber ingredients were industrial grades and used as received.

\subsection{Methods}

\subsubsection{Pyrolysis of DDGS}

The DDGS was pre-dried at $80^{\circ} \mathrm{C}$ in an air circulating oven for $24 \mathrm{hrs}$, as reported in the literature [33]. This was pyrolyzed at OPTI-TECH using a Carbolite Gero pyrolyzer (model GLO 10/11-1G, max. temperature $1000^{\circ} \mathrm{C}$ ) at $900^{\circ} \mathrm{C}$ for 15 mints at a ramp rate of $7.5^{\circ} \mathrm{C} / \mathrm{mints}$, after which it was ball milled in a FRITSCH Pulverisette Ball mill for 4 hrs. This milled biocarbon was utilized for the preparation of composites. This preparation method is environmentally friendly and economical than the conventional fillers $[11,34,35]$.

\subsubsection{Preparation of natural rubber vulcanizates}

The natural rubber vulcanizates were prepared as per the formulations given in Table 1 [36]. The appropriate proportions of the ingredients were mixed with natural rubber in a Haake internal mixer for 10 minutes at $60^{\circ} \mathrm{C}$, followed by sheeting out the compounded rubber on a two-roll mill. During the preparation of hybrid composites, the $15 \mathrm{phr}$ of biocarbon and $15 \mathrm{phr}$ of carbon black were mixed well prior to processing to ensure uniform dispersion of hybrid filler. All the masterbatch were compression molded at $150{ }^{\circ} \mathrm{C}$ for 8 mints using a Carver compression molding machine.

\section{Characterization of biocarbon and natural rubber vulcanizates}

The morphology of biocarbon particles before and after ball milling was studied using a Phenom ProX (Phenom-World BV) scanning electron microscope. The images were then analyzed using the ParticleMetric particle size analysis application of Phenom-World B.V. to gather the shape and size data of the particles in each image. The number of particles measured for each sample was typically more than 3000 .

For the measurement of tensile strength, modulus, elongation at break and tear strength of the materials, an Instron 3382 Universal testing machine was utilized. Tensile and tear properties were measured using samples punched out from the molded sheets using ASTM Die-C, and the testing was conducted as per ASTM D412 (Type C) and ASTM D624 (Type C), respectively. The viscoelastic characteristics of the NR vulcanizates were studied using a dynamic mechanical analyzer (DMA Q800 from TA-Instruments, USA) from -90 to $100^{\circ} \mathrm{C}$ with a heating rate of $3{ }^{\circ} \mathrm{C} /$ mints. $20 \mathrm{~mm} \times 6 \mathrm{~mm} \times 3 \mathrm{~mm}$ samples were used in tension thin film mode at a frequency of $1 \mathrm{~Hz}$ and a strain rate of $0.1 \%$. The dynamic properties that are related to wet skid and rolling resistance of the neat natural rubber and composites were investigated using a dynamic mechanical analyzer. Thermogravimetric analysis (TGA) was carried out to investigate the degradation mechanism using a TA Q500 thermal analyzer, USA. The TGA analysis was conducted from room temperature to $600^{\circ} \mathrm{C}$ with a heating rate of $20^{\circ} \mathrm{C} / \mathrm{mints}$ in a nitrogen atmosphere and from 600 to $900^{\circ} \mathrm{C}$ in an oxygen atmosphere. TGA-FTIR experiments were performed using a TGA (TA 5500

Table 1. Formulation of natural rubber vulcanizates.

\begin{tabular}{|c|c|c|c|c|c|c|}
\hline Ingredients & NR neat & NR_CB_15 & NR_CB_30 & NR_BC_30 & NR_BC-CB_30 & $\begin{array}{l}\text { Mixing time } \\
\text { [min] }\end{array}$ \\
\hline Natural rubber & 100 & 100 & 100 & 100 & 100 & 1 \\
\hline Carbon black $\quad[\mathrm{phr}]$ & & 15 & 30 & & & 2 \\
\hline Biocarbon & & & & 30 & & 2 \\
\hline Hybrid filler & & & & & 30 & 2 \\
\hline Zinc oxide & 4 & 4 & 4 & 4 & 4 & 2 \\
\hline Stearic acid & 2 & 2 & 2 & 2 & 2 & 1 \\
\hline TMTD & 1 & 1 & 1 & 1 & 1 & 1 \\
\hline Sulphur & 1 & 1 & 1 & 1 & 1 & 1 \\
\hline
\end{tabular}


thermogravimetric analyzer) coupled with a Thermo Scientific Nicolet 6700 FTIR spectrometer. The TGA was conducted from room temperature to $800^{\circ} \mathrm{C}$ in a nitrogen atmosphere, and from 800 to $1000^{\circ} \mathrm{C}$ in an oxygen atmosphere, and the evolved gases were analyzed using FTIR. In addition, the usage of different atmospheres would result in different thermal degradation behaviors, and the oxygen atmosphere will accelerate the degradation process [37]. The oxygen was supplied at $800^{\circ} \mathrm{C}$ to analyze the burning mechanism of neat NR and all the composites. The morphology of cryo-fractured surfaces of all the composites was analyzed using a Phenom ProX (Phenom-World BV) scanning electron microscope.

The crosslink density of the vulcanized samples was studied by solvent swelling. Initial weights $\left(W_{1}\right)$ of the samples were measured, and then they were immersed in toluene at room temperature. After $72 \mathrm{hrs,}$ the specimens were taken from the toluene and the surfaces of the samples were wiped to eliminate the solvent. Swollen weights $\left(W_{2}\right)$ of the vulcanizates were measured, and the volume swelling percentage was determined using Equation (1):

Swelling by volume $[\%]=\left(\frac{W_{2}}{W_{1}}-1\right) \frac{d_{\mathrm{r}}}{d_{\mathrm{s}}} \cdot 100$

where $d_{\mathrm{r}}$ is density of rubber, $d_{\mathrm{S}}$ the density of toluene. Then, the vulcanizates were dried at $60^{\circ} \mathrm{C}$ for $48 \mathrm{hrs}$ to find the de-swollen weight of the samples. The crosslink density was calculated with the help of the Flory-Rehner equation [38, 39] (Equation (2)):

$-\ln \left(1-v_{\mathrm{r}}\right)-v_{\mathrm{r}}-\chi v_{\mathrm{r}}^{2}=2 v_{\mathrm{s}} \eta\left(v_{\mathrm{r}}^{1 / 3}-2 \frac{v_{\mathrm{r}}}{f}\right)$

Hildebrand equation (Equation (3)) was employed to calculate $\chi$, the Flory-Huggins solvent rubber interaction parameter, $\eta=$ crosslink density of rubber $\left[\mathrm{mol} \cdot \mathrm{cm}^{-3}\right.$ ), $f=$ functionality of crosslinks ( 4 for sulfur curing system):

$\chi=\frac{v_{\mathrm{s}}}{R T}\left(\delta_{\mathrm{s}}-\delta_{\mathrm{r}}\right)^{2}$

where $R$ is universal gas constant, $T$ the temperature $[\mathrm{K}], v_{\mathrm{s}}$ is the molar volume of the toluene, $\delta_{\mathrm{s}}$ and $\delta_{\mathrm{r}}$ are solubility parameter of toluene, and natural rubber respectively. The volume fraction of rubber $\left(v_{\mathrm{r}}\right)$, was calculated using the Ellis and Welding equation [40] (Equation (4)):

Volume fraction, $v_{\mathrm{r}}=\frac{\frac{D-F T}{d_{\mathrm{r}}}}{\frac{D-F T}{d_{\mathrm{r}}}+\frac{A_{0}}{d_{\mathrm{s}}}}$

where $D$ is de-swollen weight, $F$ the weight fraction of the insoluble components calculated using the formulation, $T$ is the initial vulcanizate weight, and $A_{0}$ is the weight of absorbed solvent.

\section{Results and discussion}

\subsection{Morphological characterization of DDGS biocarbon}

In order to analyze the morphology and particle size distribution of DDGS biocarbon before and after ball milling, SEM was carried out. The particle size distribution of the biocarbon before and after $4 \mathrm{hrs}$ of ball milling is given in Table 2, which was calculated from the SEM image-based particle counting. The SEM images shown in Figure 1 depicts irregularsized biocarbon particles, and more than $60 \%$ of them had less than $1 \mu \mathrm{m}$ size. $4 \mathrm{hrs}$ of ball-milling was conducted to ensure the size reduction of higher sized particles. The largest particle size was reduced to $1 / 3^{\text {rd }}$ with 4 hrs of ball milling, which could impart better properties and homogeneity in the natural rubber matrix [41].

\subsection{Mechanical properties of natural rubber vulcanizates}

Tensile properties

The mechanical properties of natural rubber vulcanizates were analyzed using a universal testing machine. The stress strain curves and the tensile properties of the vulcanizates are given in Figure 2 and Table 3 respectively. As compared to neat NR vulcanizate, the tensile strength and elongation at break of natural rubber biocarbon composite were decreased. In the case of NR_BC_30, the larger particle size of biocarbon prevented the crosslinking, and hence decreased the tensile properties. In general, the tensile strength of composite decreases with the

Table 2. Particle size distribution of DDGS biocarbon before and after 4 hrs of ball milling.

\begin{tabular}{|l|c|c|c|c|c|}
\hline \multicolumn{1}{|c|}{ Sample designation } & $\begin{array}{c}\text { Less than } \mathbf{5 0 0} \mathbf{~ n m} \\
{[\mathbf{\%}]}\end{array}$ & $\begin{array}{c}\text { Less than } \mathbf{7 5 0} \mathbf{~ n m} \\
{[\mathbf{\%}]}\end{array}$ & $\begin{array}{c}\text { Less than } \mathbf{1} \boldsymbol{\mu m} \\
{[\mathbf{\%}]}\end{array}$ & $\begin{array}{c}\text { Less than } \mathbf{1 . 5} \boldsymbol{\mu m} \\
{[\mathbf{\%}]}\end{array}$ & $\begin{array}{c}\text { Largest particle size } \\
{[\boldsymbol{\mu} \mathbf{m}]}\end{array}$ \\
\hline DDGS_900 ${ }^{\circ} \mathrm{C}$ before ball milling & 17.6 & 42.1 & 57.1 & 74.1 & 14.1 \\
\hline DDGS_900 ${ }^{\circ} \mathrm{C}$ 4hrs ball milling & 25.4 & 51.6 & 62.7 & 82.3 & 4.5 \\
\hline
\end{tabular}




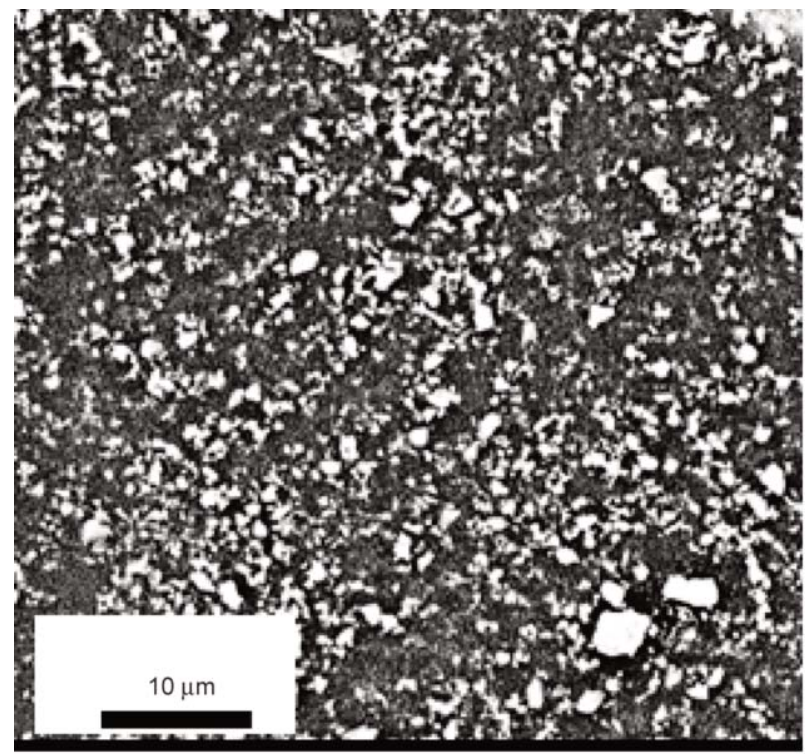

a)

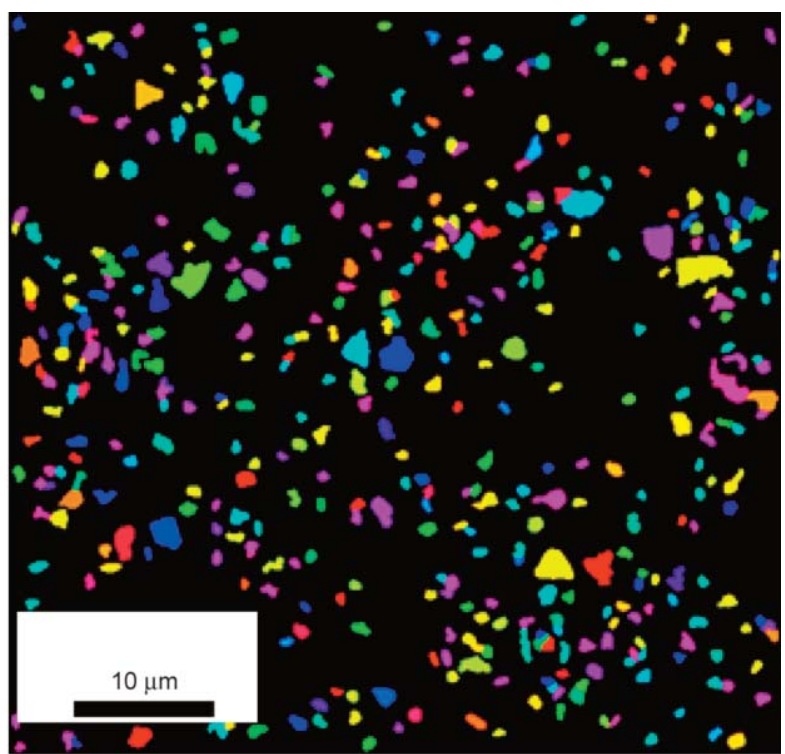

b)

Figure 1. (a) SEM image of 4 hrs ball-milled DDGS biocarbon and (b) illustrates the particles recognized from the SEM image on the left; used for analyzing the particle size distribution (Table 2).

increase in particle size of filler [42]. As a result of this, the reinforcing effect is less in biocarbon composites as compared to carbon black, as reported in the literature [7]. Research is being conducted to find economically feasible methods to obtain a particle size similar to the nodules of carbon black from biooil [43]. The reinforcement of carbon black is well known, and the tensile strength of carbon black filled composites (NR_CB_30) was improved by $40 \%$ with the addition of 30 phr of carbon black. Jong et al. [7] reported similar results at $10 \mathrm{wt} \%$ addition of coconut shell, and wood-based biocarbon showed less tensile strength than the corresponding carbon black composites based on natural rubber. In the case of hybrid composites, the tensile strength was increased slightly higher than the neat NR because of the carbon black inclusion. In order to have a good comparison, NR_CB_15 composite is also included in Table 3. The tensile strengths of the NR_CB_15 and hybrid composites revealed similar results showing that the contribution from biocarbon is negligible in terms of tensile strength properties. The elongation at break (EB) of all the vulcanizates shown in Table 3 were inversely proportional to the tensile strength properties. As the unfilled NR possesses adequate mobility and hence neat natural rubber exhibited $1000 \%$ of elongation at break. In the case of the biocarbon (NR_BC_30) and carbon black composites (NR_CB_30), the elongation at break was reduced to 760 and $675 \%$ respectively than the neat NR. The reduction in $E B$ occurred due to the reduced mobility of the rubber chains after the addition of filler. The partial replacement of biocarbon with carbon black caused a comparatively higher $E B$ of $750 \%$ than that of NR_CB_30. The modulus at 100, 200 and 300\% elongation of all the natural rubber composites were improved with filler addition. In the case of hybrid composites, the $100 \%$ modulus increased by $90 \%$ with the addition of $30 \mathrm{phr}$ of biocarbon and 200 and $300 \%$ moduli were increased by 65 and $82 \%$, respectively. The hybrid composites had intermediate modulus properties between biocarbon and carbon black composites. Similar observation was noticed in hybrid composites of carbon black and rice husk derived

Table 3. Tensile and tear strength properties of natural rubber vulcanizates.

\begin{tabular}{|l|c|c|c|c|c|c|}
\hline $\begin{array}{c}\text { Sample } \\
\text { designation }\end{array}$ & $\begin{array}{c}\boldsymbol{T S} \\
{[\mathbf{M P a}]}\end{array}$ & $\begin{array}{c}\boldsymbol{E B} \\
{[\%]}\end{array}$ & $\begin{array}{c}\text { Mod at 100\% } \\
{[\mathbf{M P a}]}\end{array}$ & $\begin{array}{c}\text { Mod at 200\% } \\
{[\mathbf{M P a}]}\end{array}$ & $\begin{array}{c}\text { Mod at 300\% } \\
{[\mathbf{M P a}]}\end{array}$ & $\begin{array}{c}\text { Tear strength } \\
{[\mathbf{N} / \mathbf{m m}]}\end{array}$ \\
\hline NR neat & $19.5 \pm 1$ & $1000 \pm 95$ & $1.00 \pm 0.1$ & $1.55 \pm 0.16$ & $2.2 \pm 0.19$ & $44 \pm 4$ \\
\hline NR_CB_15 & $21.0 \pm 1$ & $870 \pm 65$ & $1.40 \pm 0.1$ & $2.10 \pm 0.21$ & $3.1 \pm 0.17$ & $52 \pm 3$ \\
\hline NR_BC_30 & $15.6 \pm 2$ & $770 \pm 70$ & $1.35 \pm 0.2$ & $2.66 \pm 0.19$ & $3.2 \pm 0.29$ & $49 \pm 5$ \\
\hline NR_CB_30 & $29.5 \pm 3$ & $675 \pm 30$ & $2.00 \pm 0.2$ & $3.20 \pm 0.29$ & $5.0 \pm 0.40$ & $71 \pm 6$ \\
\hline NR_BC-CB_30 & $21.4 \pm 2$ & $750 \pm 73$ & $1.90 \pm 0.3$ & $2.50 \pm 0.20$ & $4.0 \pm 0.38$ & $51 \pm 5$ \\
\hline
\end{tabular}




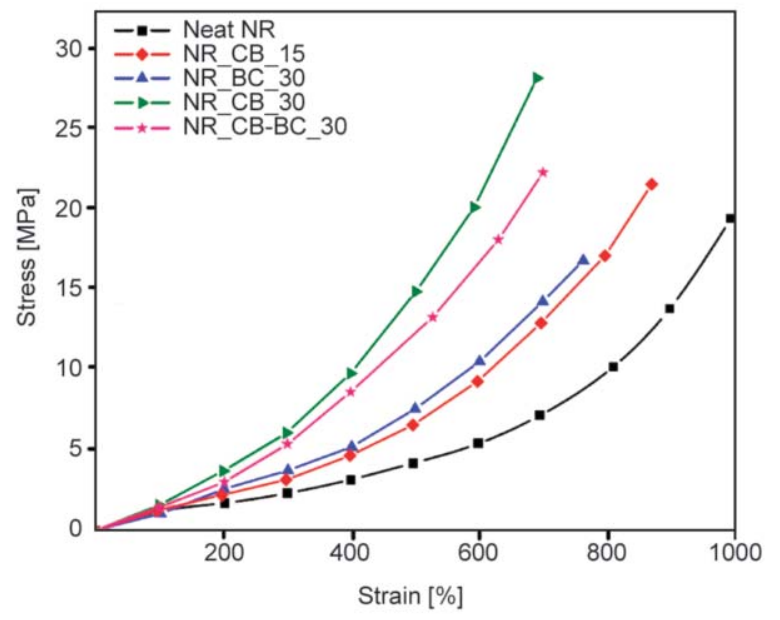

Figure 2. Stress strain curves of natural rubber vulcanizates.

nanocellulose based NR vulcanizates where they used $30 \mathrm{wt} \%$ equal mixture of carbon black and nanocellulose and resultant tensile strength was lower than the $\mathrm{CB}$ vulcanizates and neat natural rubber [13].

\subsection{Tear strength}

The tear strength of natural rubber vulcanizates was measured, and results are given in Table 3. Neat NR shows a tear strength of $44 \mathrm{~N} / \mathrm{mm}$. With the addition of $30 \mathrm{phr}$ of biocarbon, this was improved by $10 \%$. Biocarbon has a larger particle size than carbon black and had a particle size distribution from $800 \mathrm{~nm}$ to $2.0 \mu \mathrm{m}$. Hence, the particles with smaller size promoted reinforcement and improved the crosslink density, while, the larger particles prevent the crosslinking of polymer chains. Carbon black is a proven reinforcing filler that imparts significant tear strength to the matrix, and in this case, gave a $61 \%$ improvement in tear strength as compared to neat NR [44]. The hybrid composites containing a mixture of $30 \mathrm{phr}$ of

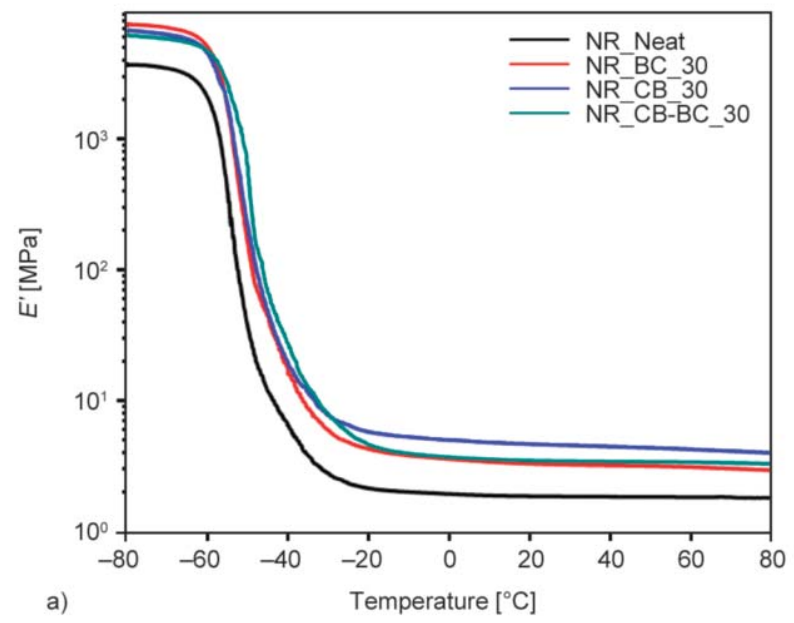

biocarbon and carbon black resulted in an $18 \%$ improvement in tear strength. The decrease in tear strength of biocarbon composites were due to the reduced polymer filler interaction [13].

\subsection{Dynamic mechanical analysis (DMA)}

The dynamic mechanical properties of the natural rubber vulcanizates were investigated using the DMA analyzer. The storage modulus and $\tan \delta$ graphs of the natural rubber vulcanizates are given in Figure 3. In the glassy region of composites, a significant increase in storage modulus was found with biocarbon composites due to the higher modulus of biocarbon than the carbon black. Due to the higher reinforcing effect of carbon black particles, the storage modulus was prominent in the rubbery region than the biocarbon and hybrid composites. Interestingly, the hybrid composites revealed a lower modulus in the glassy state (below $T_{\mathrm{g}}$ ) as compared to both the carbon black and biocarbon composites. At higher loading, carbon black composites show agglomeration; this agglomerated network promotes tensile modulus [45]. Whereas biocarbon does not show any agglomeration, but, instead, it possesses higher modulus due to the selection of comparatively higher temperatureinduced preparation [46]. However, in the hybrid filler, the agglomeration effect of carbon black (15 phr) was diluted by the inclusion of 15 phr of biocarbon, and this promoted a better distribution of both the fillers as compared to the carbon black composites. Moreover, the hybrid fillers show less networking than the carbon black composites, and hence exhibit reduced visco-elastic dissipation [31], as shown in the schematic diagram (Figure 4). This shows the networking effect of carbon black, biocarbon, and

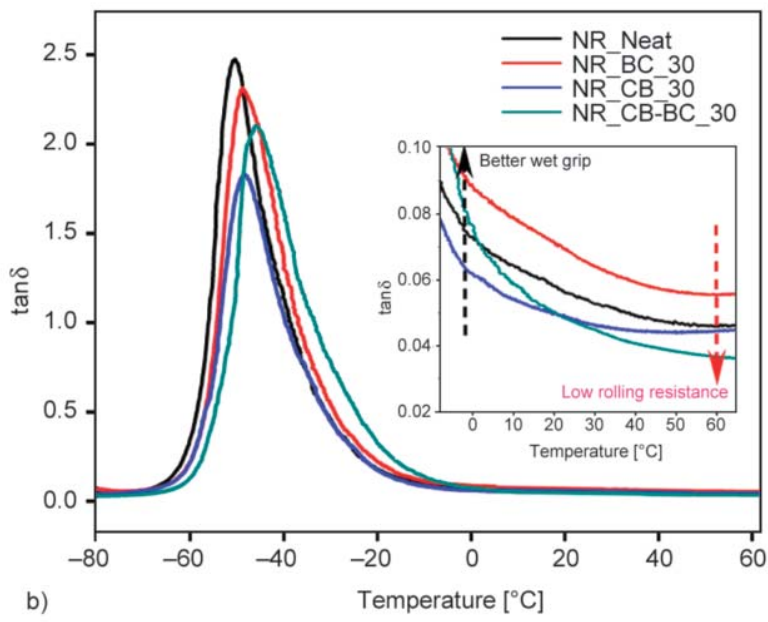

Figure 3. (a) Storage modulus and (b) $\tan \delta$ of natural rubber vulcanizates. 
hybrid filler on the viscoelastic properties of the vulcanizates. It was a proven fact that the carbon black addition had a negative role in increasing rolling resistance due to the network formation, and the addition of silica-based fillers helped to reduce the rolling resistance properties [47, 48]. Bhattacharya and Bhowmick studied the role of hybrid filler based on nanoclay and carbon black in natural rubber matrix and concluded that the good networking and synergy of both helped in the improvement in dynamic mechanical properties [44]. It is reported that a good balance of dynamic mechanical properties can be achieved by the incorporation of hybrid fillers [49]. In the case of NR_CB_30, better networking is possible due to the unique structure (physical characteristic) of carbon black. As the biocarbon possesses a range of particle sizes from $800 \mathrm{~nm}-1.5 \mu \mathrm{m}$, the larger particle size prevents network formation. In addition to that, ash present in the DDGS biomass contains silicates, and this may be preventing the filler network formation [50, 51]. An optimum network formation is essential to ensure adequate tensile properties. Interestingly, in the case of hybrid composites, the synergistic effects of carbon black and lower sized particles promote the formation of smaller networks. As compared to the larger networks, smaller networks possess less rolling friction. Rolling friction or resistance is created in tires when more surface area is in contact with the road $[47,52]$. Also, the incorporation of $30 \mathrm{phr}$ of carbon black in the NR matrix may show some agglomeration as compared to hybrid filler (15 phr of carbon black and biocarbon).

The $\tan \delta$ values at $0^{\circ} \mathrm{C}$ (wet grip) and $60^{\circ} \mathrm{C}$ (rolling resistance) for all the vulcanizates were analyzed.

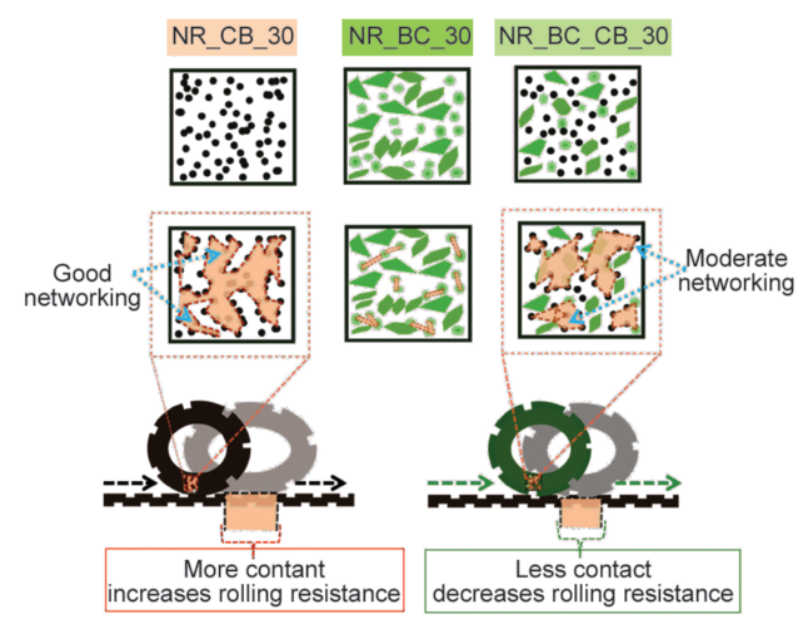

Figure 4. Schematic representation of expected networking effect of carbon black, biocarbon and hybrid filler in natural rubber vulcanizates.
A very good balance between low rolling resistance and good wet grip is essential to reduce fuel consumption and to increase skid safety [38]. In terms of the higher wet skid resistance as well as low rolling resistance properties, the hybrid biocarbon composite exhibited improved performance than the other vulcanizates making it a suitable material for tire application.

\subsection{Thermogravimetric analysis (TGA)}

The thermal decomposition of NR vulcanizates was studied using thermogravimetric analysis, and the weight loss versus temperature graph and its derivative curves are given in Figure 5. The thermogravimetric analysis describes the degradation pathway of natural rubber vulcanizates in nitrogen (25$\left.600^{\circ} \mathrm{C}\right)$ and oxygen $\left(600-900^{\circ} \mathrm{C}\right)$ atmospheres. Due to the incorporation of filler, all the natural rubber composites show a similar trend different from the neat NR matrix. The residue observed at $900^{\circ} \mathrm{C}$ directly related to the ash content of individual components. The neat natural rubber contains almost 3\% ash coming from the $\mathrm{ZnO}$, which is used as an activator for the curing of natural rubber. Carbon black has negligible ash, and hence a slight increase in residue in NR_CB_30 composites. Moreover, the biocarbon based composites resulted in higher residue, which is proportional to the percentage of biocarbon. The actual composition of all the composites can clearly be reverse-engineered from the residue content obtained at $900^{\circ} \mathrm{C}$.

Figure $5 \mathrm{~b}$ shows that the onset degradation temperature of $\mathrm{NR}\left(376^{\circ} \mathrm{C}\right)$ was not affected by the addition of carbon black $\left(376^{\circ} \mathrm{C}\right)$ but is slightly increased $\left(380^{\circ} \mathrm{C}\right)$ with biocarbon addition [53]. From the peak heights of the DTG curves, it is clear that the rate of degradation is affected by the addition of filler. In the case of NR_CB_30 and NR_BC_30, the DTG peak height was decreased and showed a similar rate with a slight shift in temperature for biocarbon composites. This confirms that, in terms of the thermal degradation mechanism, carbon black and biocarbon have a similar action on the NR matrix, and biocarbon composites exhibited better thermal stability. Interestingly, in the case of hybrid composites, the DTG peak height was again reduced as the synergy of particles having different sizes was able to prevent degradation of the natural rubber matrix to some extent. From the DTG curve of NR_BC_CB_30 (15 phr $\mathrm{BC})$, the optimum dosage of biocarbon required for maximum thermal stability was found to be $15 \mathrm{phr}$, 

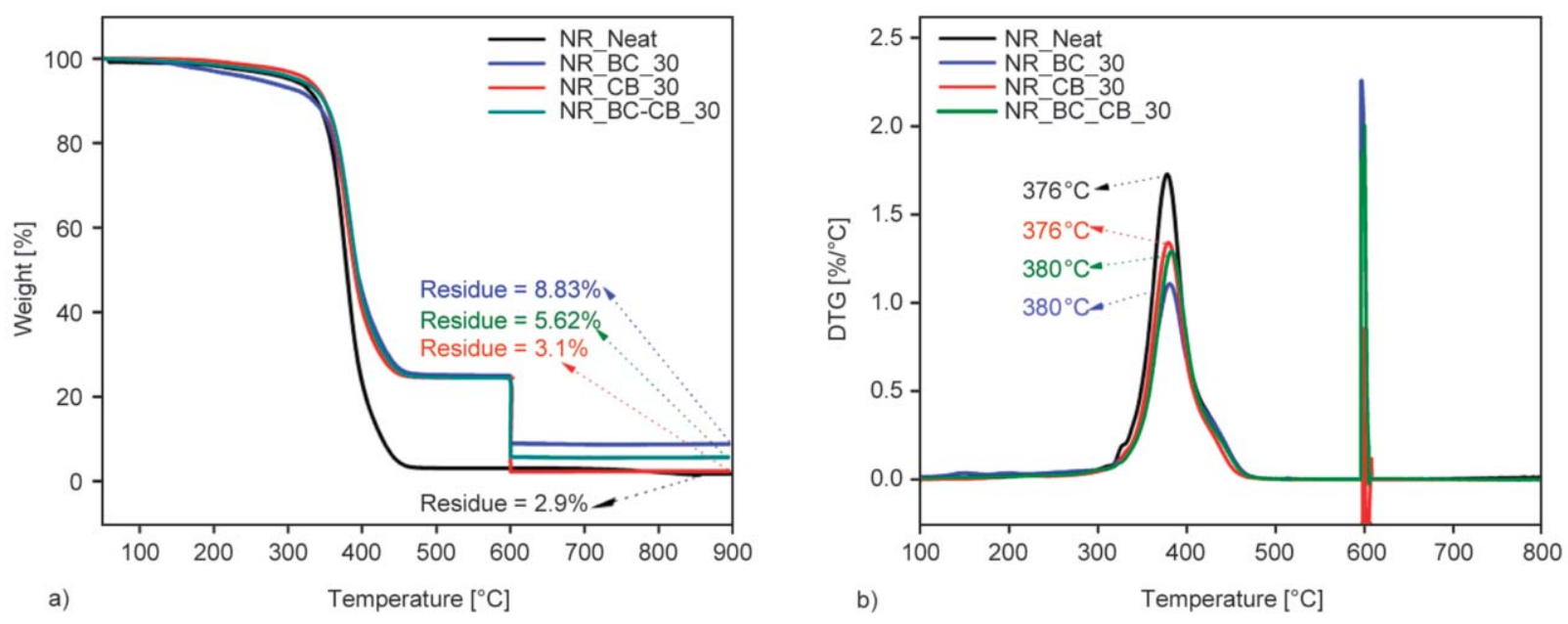

Figure 5. (a) TGA and (b) DTG of natural rubber vulcanizates.

and further addition did not affect the matrix, as seen in the case of NR_BC_30 (30phr BC). The sharp peak observed at $600^{\circ} \mathrm{C}$ is because of the purging of oxygen to ensure the degradation of all the carbonaceous content.

\subsection{TGA-FTIR analysis of natural rubber vulcanizates}

The 3D images of the IR spectra of the evolved gases obtained from the TGA of the natural rubber vulcan-
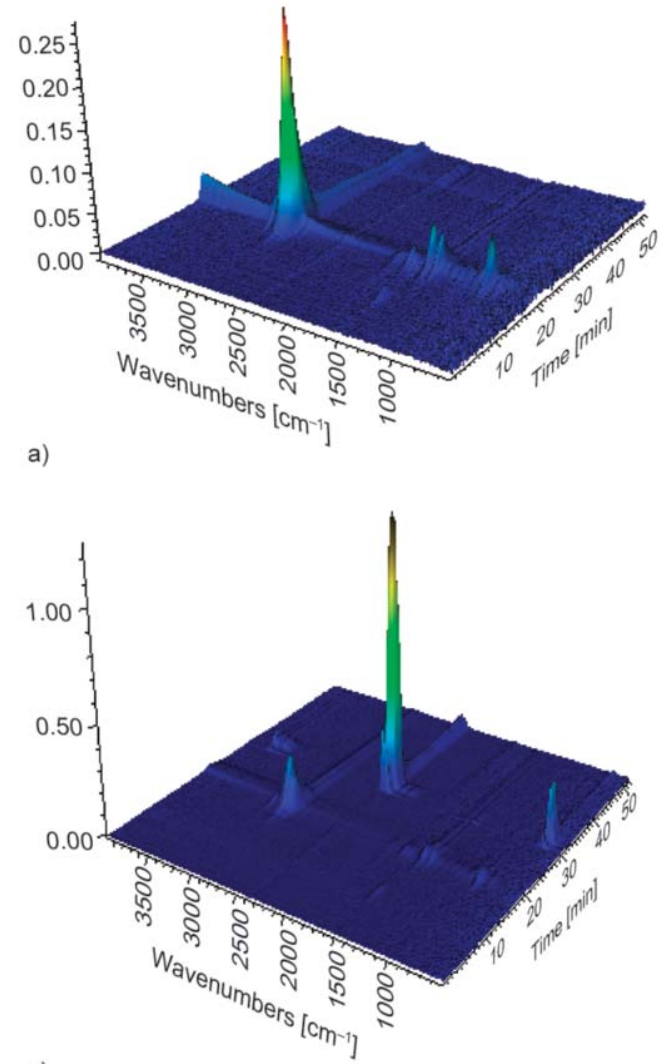

Figure 6. TGA-FTIR spectra of (a) NR_Neat, (b) NR_BC_30, (c) NR_CB_30, and (d) NR_BC-CB_30. izates are shown in Figure 6a-6d, and the GramSchmidt curve of the evolved gases during the thermal degradation is in Figure 7a. Gram-Schmidt curves are obtained by plotting the integration of the absorbance bands from each spectrum as a function of time. These curves depict details about the dominant volatiles from all the natural rubber vulcanizates. The initial peaks at $500 \mathrm{~cm}^{-1}$ and the continuing smaller peaks ranging from 3500 to $4000 \mathrm{~cm}^{-1}$ are characteristic of water present as moisture within the
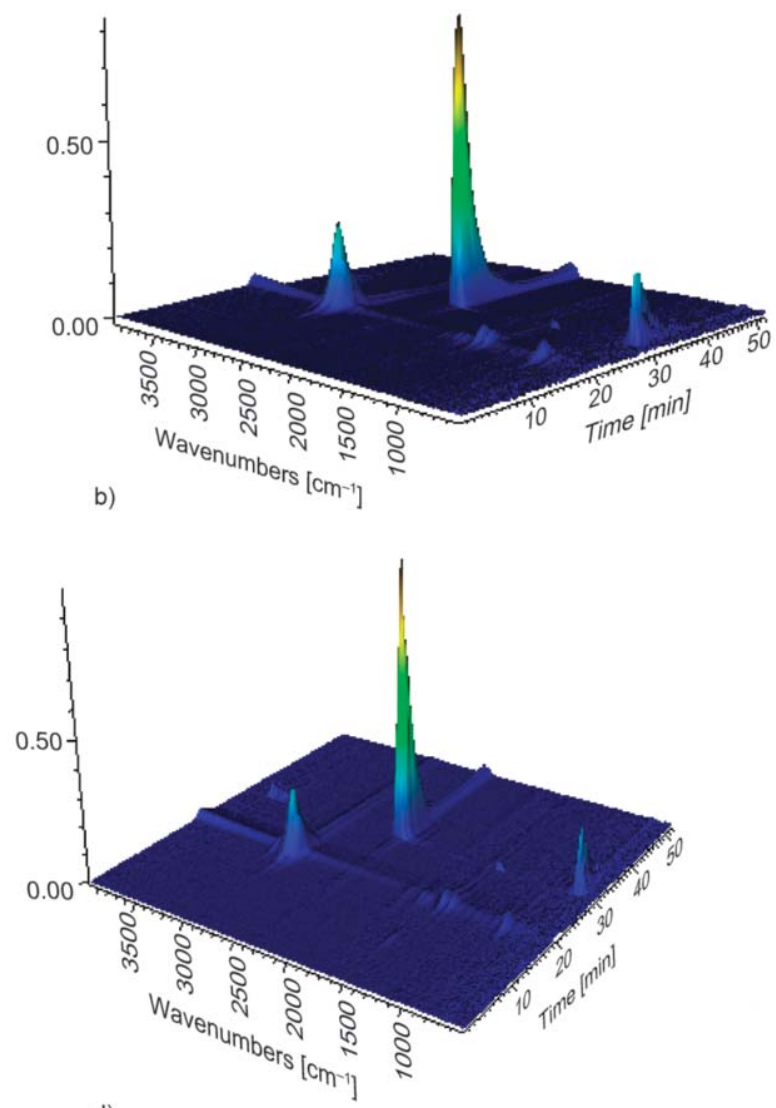

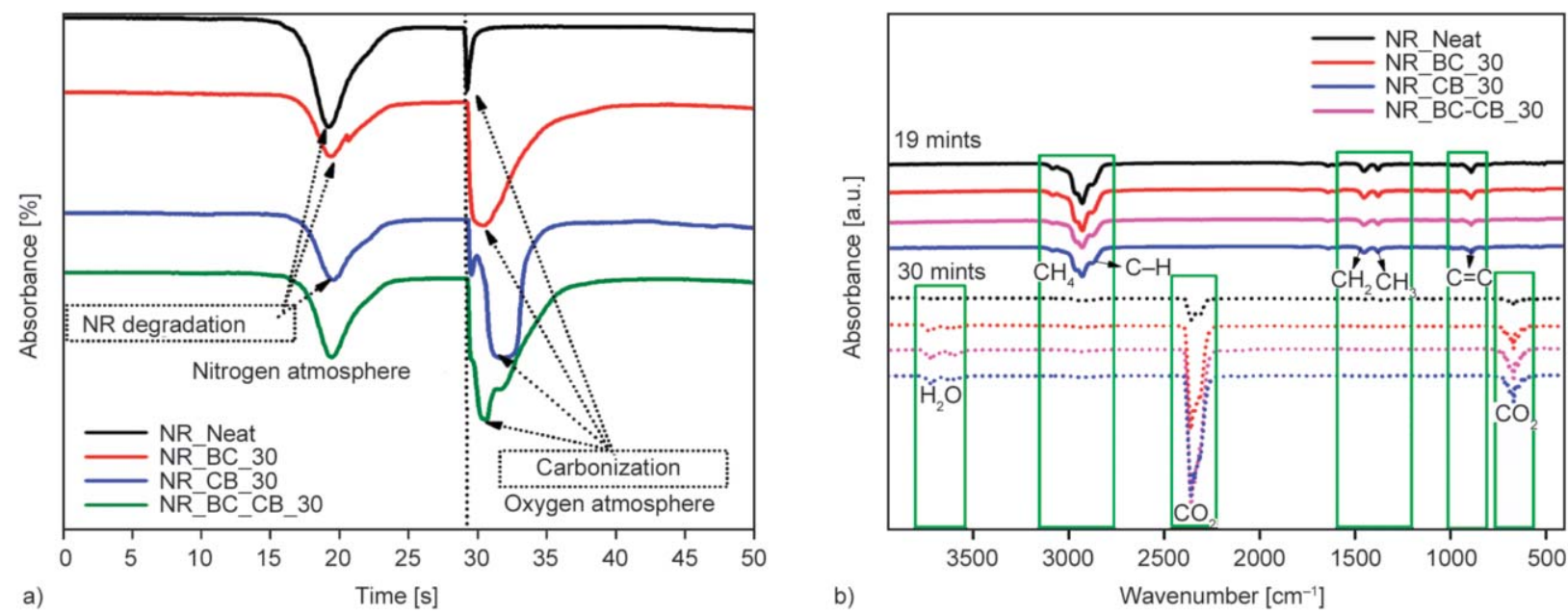

Figure 7. (a) Gram-Schmidt curves and (b) FTIR absorbance peaks (19 and 30 mints) obtained during degradation of NR vulcanizates.

vulcanizates. There are two different peaks appearing on Gram-Schmidt curves. The peak at 18-21 mints corresponds to the gases evolved during the degradation of vulcanizates in a nitrogen atmosphere. The peaks at 19 and 30 mints are shown separately in Figure $7 \mathrm{~b}$. The peaks obtained at 19 mints showed similar behavior in all the vulcanizates, and indicate the presence of $\mathrm{CH}_{4}, \mathrm{C}-\mathrm{H}, \mathrm{CH}_{2}, \mathrm{CH}_{3}$, and $\mathrm{C}=\mathrm{C}$ bonds, as shown in Figure 7a. In order to differentiate the composite degradation with the neat vulcanizate, oxygen was supplied at $800^{\circ} \mathrm{C}$, and the combustion process was initiated. The second peaks of all the curves observed at 30-33 min present in Figure 7a corresponds to degradation products obtained in the oxygen atmosphere. These curves gave an overview of the volatile production, and the most dominant volatile was $\mathrm{CO}_{2}$ produced due to the combustion of carbonaceous fillers. As compared to the neat NR, the most significant changes were observed in the absorbance of $\mathrm{CO}_{2}$ group at 2300 and $685 \mathrm{~cm}^{-1}$ where the intensities of $\mathrm{CO}_{2}$ increased with the addition of filler [33].

\subsection{Scanning electron microscopy}

Scanning electron microscopy was utilized to analyze the comparative morphology of cryo-fractured surfaces of a natural rubber vulcanizate, as shown in Figure 8. In the case of NR_Neat, ZnO particles were observed on the fractured surfaces. With the incorporation of $30 \mathrm{phr}$ of carbonaceous filler, the fractured surfaces were visible with the dispersed particles in all the composites, as given in Figure $8 b-8 c$. In the case of biocarbon composites, more than $50 \%$ of the particles had a particle size of less than $750 \mathrm{~nm}$, and almost $20 \%$ of the particles have a particle size of more than $1.5 \mu \mathrm{m}$ (Table 2). This higher particle size and the wide range particle size distribution helped the biocarbon particles to occupy as separate individual particles in the NR matrix, and those were visible on the fractured surface (Figure $8 b$ ). As different from the biocarbon composites, the carbon black particles were having smaller particle sizes $(400 \mathrm{~nm})$. Even though the carbon black disperses well in the NR, due to the higher surface energy of nanoparticles of carbon black showed some agglomeration networks and resulted less distribution of fillers than the biocarbon.

The high biocarbon filled NR matrix (NR_BC_30) (Figure 8d) decreases the strength properties due to the larger particle size, while in the $\mathrm{CB}$ filled composite (NR_CB 30), the higher loading affected the dispersion due to agglomeration. Also, the hybrid filler containing spherical (nano) carbon black particles and irregular shaped (nano and micro) particles prevents the chances of agglomeration of carbon black particles. In the case of hybrid composite (NR_BC-CB_30) (Figure 8d), the negative effect from the agglomeration of carbon black (15 phr) as well as the larger particle size of biocarbon (15 phr) was reduced, which was beneficial in terms of strength and dispersion, and better distribution of biocarbon filler and better dispersion of carbon black in natural rubber was equally benefited in hybrid composites. Moreover, this morphology can be correlated with the mechanical properties of NR vulcanizate given earlier. 


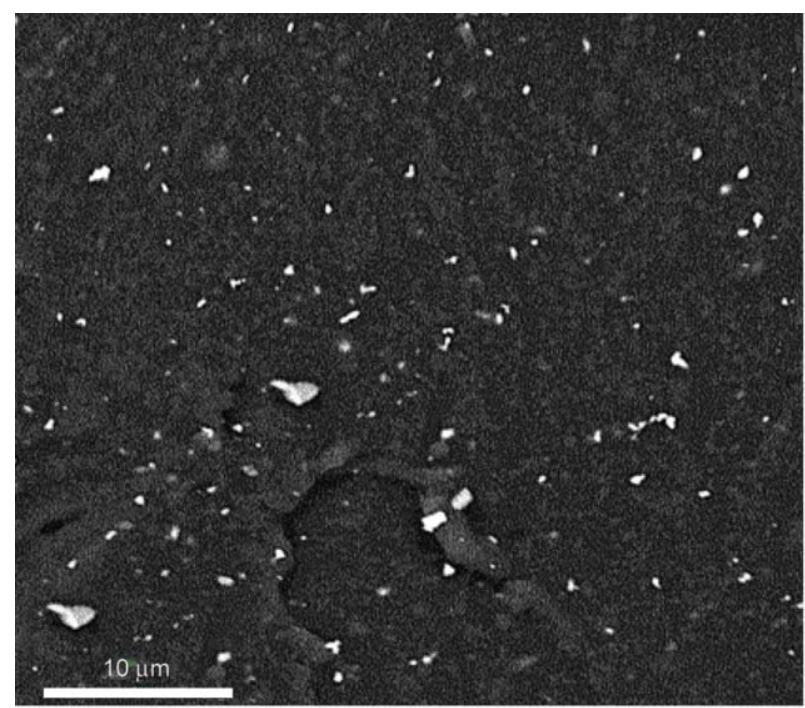

a)

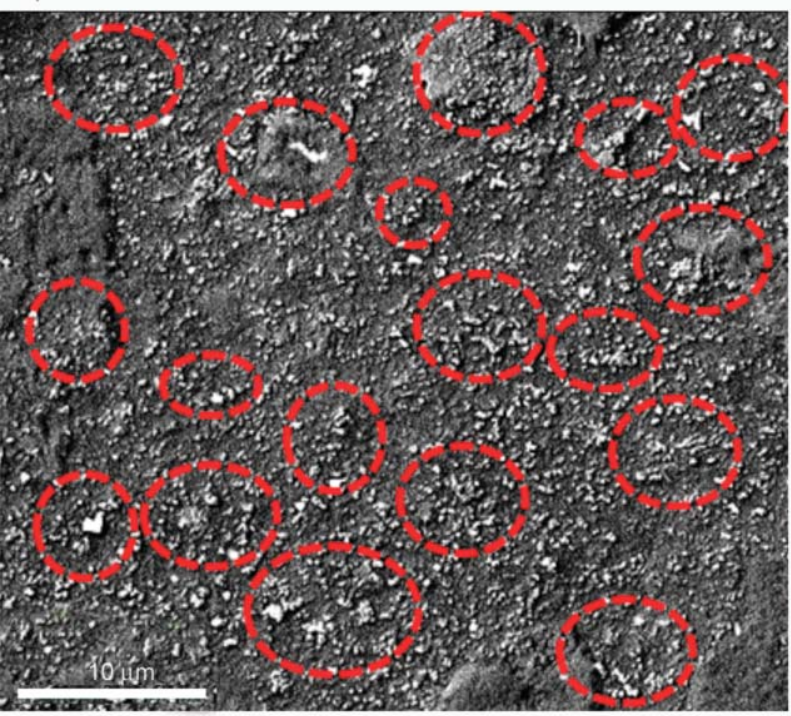

c)

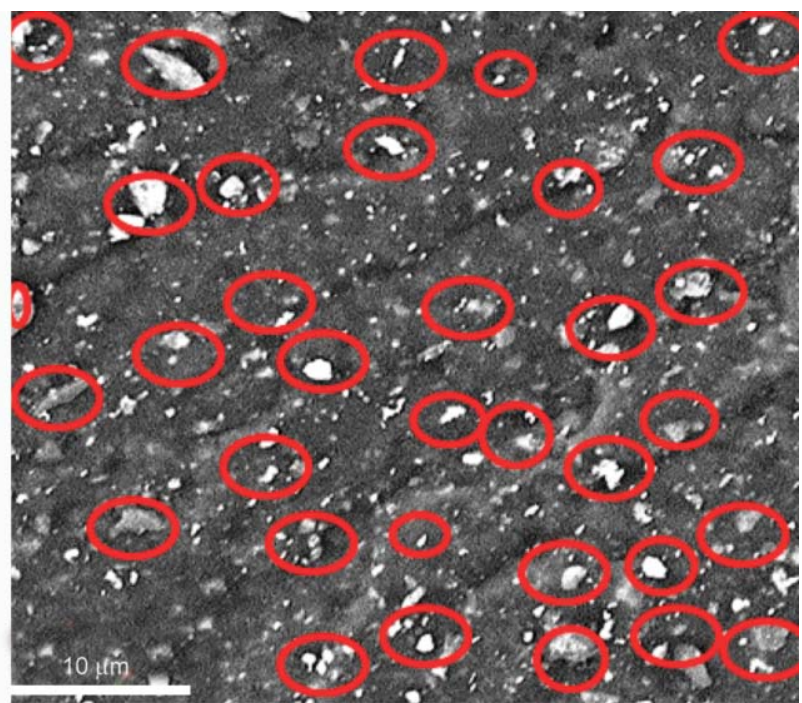

b)

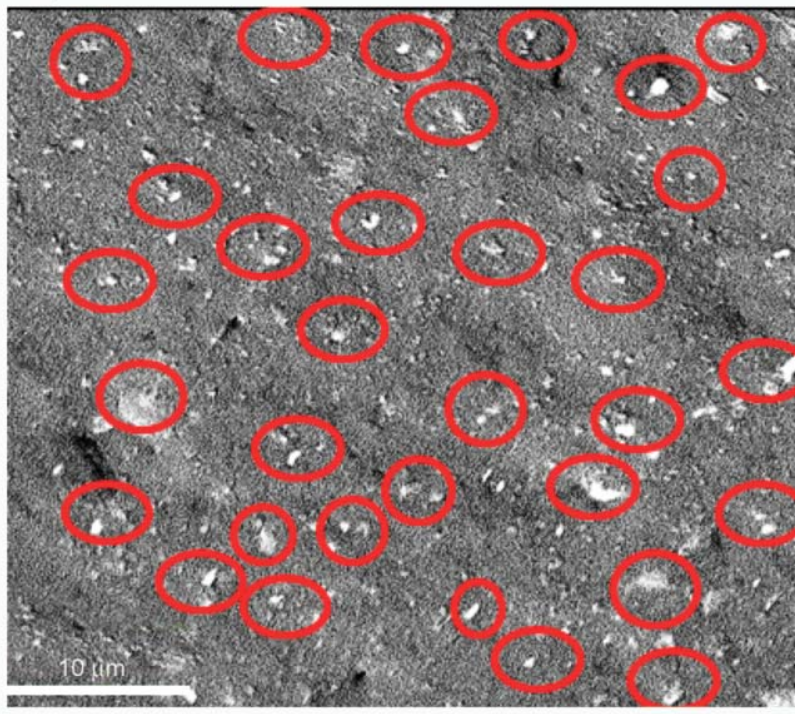

d) (c) NR_CB_30 and (d) NR_BC-CB_30.

\subsection{Swelling studies}

The swelling behavior of the neat natural rubber and composites shows a direct relationship between the polymer filler interactions and the crosslink density of the filled natural rubber vulcanizates. The swelling studies of the neat NR and filled NR with biocarbon, carbon black, and a mixture of both (hybrid filler) as reinforcing agents were conducted in toluene. From the swelling studies, the volume fraction of crosslinked polymer was calculated with the help of the Ellis and Welding equation [40] (Equation (4)) and was used for finding crosslink density using the Flory-Rehner [39] equation (Equation (2)), as explained in the experimental section. Figure 9 gives the dependency of the volume swelling on filler for the natural rubber vulcanizates. Different from the usual trend of higher swelling percentage for neat NR vulcanizate, the biocarbon based NR composites had higher swelling. The gum vulcanizate had a volume swelling of $358 \%$, and biocarbon and carbon black filled vulcanizates showed 506 and 305\%, respectively. Interestingly, in the case of hybrid composite, the swelling was found to be $350 \%$, which is slightly less than that of neat NR. Here, the larger particle size of biocarbon was balanced by the effect of dispersed carbon black. It is clear from Figure $9 b$ that the crosslink density decreases with the addition of biocarbon and increases with the addition of carbon black compared to neat natural rubber vulcanizate. Hence, the hybrid filler follows an intermediate trend in between carbon black and biocarbon composites, and is comparable with neat NR, which supports the results obtained for the tensile properties. The larger particle size of biocarbon as compared to carbon 

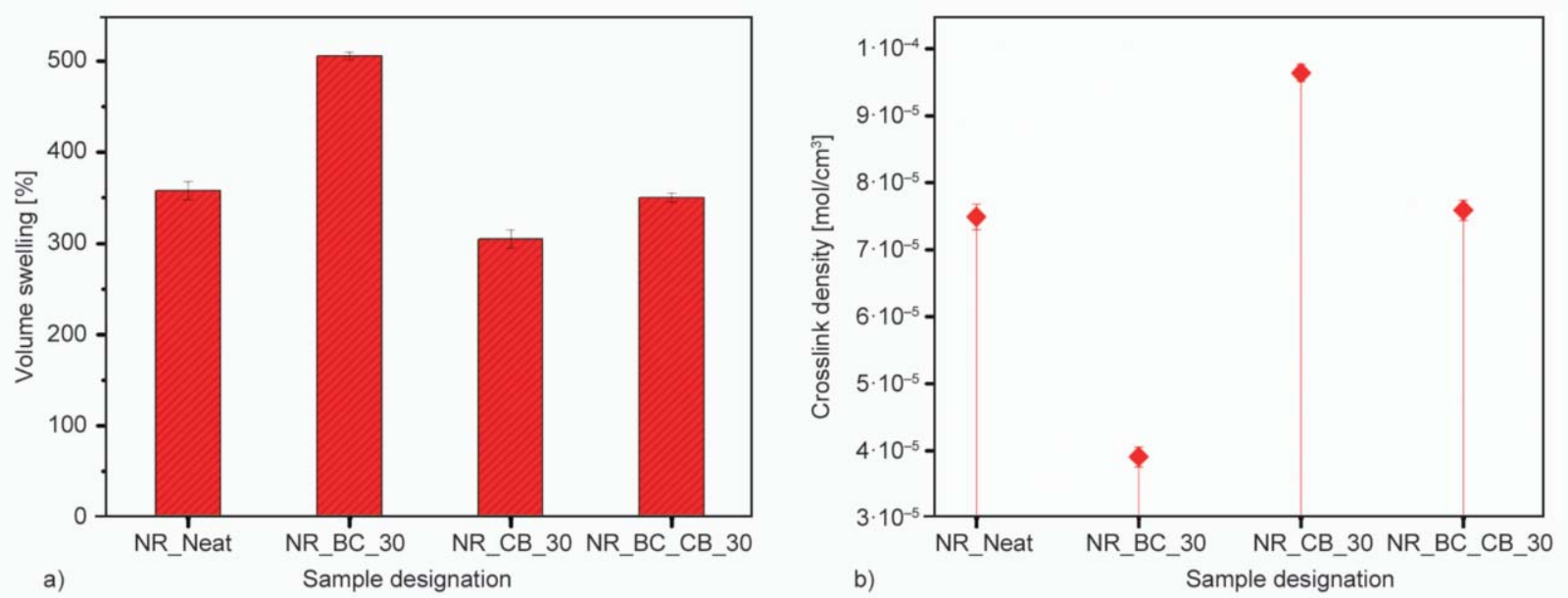

Figure 9. (a) Volume swelling and (b) crosslink densities of natural rubber vulcanizates.

black prevents crosslink formation between natural rubber polymer chains. A similar correlation between crosslink density and mechanical properties such as tensile and tear properties were previously reported in natural composites based on starch [54] and regenerated cellulose [13] as fillers.

\section{Conclusions}

The synergistic effect of sustainable biocarbon and carbon black was explored in a natural rubber matrix. Biocarbon produced from dried distiller's grains with solubles (DDGS) at $900^{\circ} \mathrm{C}$ was used along with carbon black (N762). In order to analyze the effect of biocarbon, carbon black, and hybrid filler in natural rubber, composites were fabricated with $30 \mathrm{phr}$ of filler and characterized. The hybrid composite showed intermediate mechanical properties to those of carbon black and biocarbon composites and was better than the natural rubber vulcanizate. The larger particle size of biocarbon resulted in lower crosslink density in the NR matrix and which was reflected in overall mechanical properties. Interestingly, in the case of hybrid composites, more than $100 \%$ improvement in tensile moduli was noticed at 100, 200, and $300 \%$ elongations. Moreover, the hybrid composite possessed moderate filler networking, and hence lower rolling resistance and higher wet skid resistance than the carbon black vulcanizate, which is potentially good for tire applications. In summary, this study, based on the partial replacement of carbon black using the DDGS biocarbon opens a huge scope for the utilization of waste biomasses for the preparation of sustainable fillers and their incorporation in various rubber products.

\section{Acknowledgements}

The author would like to thank the following for their financial support to carry out this work i) the Agriculture and AgriFood Canada (AAFC), Maple Leaf Food, Canada and Bank of Montreal (BMO), Canada through Bioindustrial Innovation Canada (BIC) Bioproducts AgSci Cluster Program (Project Nos 054015, 054449 and 800148); ii) the Ontario Ministry of Agriculture, Food and Rural Affairs (OMAFRA)/ University of Guelph - Bioeconomy for Industrial Uses Research Program (Project No. 030332); and the Natural Sciences and Engineering Research Council (NSERC), Canada Discovery Grants (Project Nos. 401111 and 400320).

\section{References}

[1] Ronsse F., van Hecke S., Dickinson D., Prins W.: Production and characterization of slow pyrolysis biochar: Influence of feedstock type and pyrolysis conditions. GCB Bioenergy, 5, 104-115 (2013).

https://doi.org/10.1111/gcbb.12018

[2] Liu W-J., Jiang H., Yu H-Q.: Development of biocharbased functional materials: Toward a sustainable platform carbon material. Chemical Reviews, 115, 1225112285 (2015).

https://doi.org/10.1021/acs.chemrev.5b00195

[3] Behazin E., Misra M., Mohanty A. K.: Sustainable biocomposites from pyrolyzed grass and toughened polypropylene: Structure-property relationships. ACS Omega, 2, 2191-2199 (2017). https://doi.org/10.1021/acsomega.7b00122

[4] Cha J. S., Park S. H., Jung S-C., Ryu C., Jeon J-K., Shin M-C., Park Y-K.: Production and utilization of biochar: A review. Journal of Industrial and Engineering Chemistry, 40, 1-15 (2016). https://doi.org/10.1016/j.jiec.2016.06.002

[5] Roy N., Sengupta R., Bhowmick A. K.: Modifications of carbon for polymer composites and nanocomposites. Progress in Polymer Science, 37, 781-819 (2012). https://doi.org/10.1016/j.progpolymsci.2012.02.002 
[6] Khodabakhshi S., Fulvio P. F., Andreoli E.: Carbon black reborn: Structure and chemistry for renewable energy harnessing. Carbon, 162, 604-649 (2020).

https://doi.org/10.1016/j.carbon.2020.02.058

[7] Jong L., Peterson S. C., Jackson M. A.: Utilization of porous carbons derived from coconut shell and wood in natural rubber. Journal of Polymers and the Environment, 22, 289-297 (2014).

https://doi.org/10.1007/s10924-013-0637-4

[8] Peterson S. C.: Evaluating corn starch and corn stover biochar as renewable filler in carboxylated styrene-butadiene rubber composites. Journal of Elastomers and Plastics, 44, 43-54 (2012).

https://doi.org/10.1177/0095244311414011

[9] Becker H., Herzberg F., Schulte A., Kolossa-Gehring M.: The carcinogenic potential of nanomaterials, their release from products and options for regulating them. International Journal of Hygiene and Environmental Health, 214, 231-238 (2011).

https://doi.org/10.1016/j.ijheh.2010.11.004

[10] Reijnders L.: Cleaner nanotechnology and hazard reduction of manufactured nanoparticles. Journal of Cleaner Production, 14, 124-133 (2006).

https://doi.org/10.1016/j.jclepro.2005.03.018

[11] Baan R. A.: Carcinogenic hazards from inhaled carbon black, titanium dioxide, and talc not containing asbestos or asbestiform fibers: Recent evaluations by an IARC monographs working group. Inhalation Toxicology, 19, 213-228 (2007).

https://doi.org/10.1080/08958370701497903

[12] Sahu D., Kannan G. M., Vijayaraghavan R.: Carbon black particle exhibits size dependent toxicity in human monocytes. International Journal of Inflammation, 2014, 827019/1-827019/10 (2014).

https://doi.org/10.1155/2014/827019

[13] Dominic M., Joseph R., Sabura Begum P. M., Kanoth B. P., Chandra J., Thomas S.: Green tire technology: Effect of rice husk derived nanocellulose (RHNC) in replacing carbon black $(\mathrm{CB})$ in natural rubber (NR) compounding. Carbohydrate Polymers, 230, 115620/1115620/11 (2020).

https://doi.org/10.1016/j.carbpol.2019.115620

[14] Snowdon M. R., Mohanty A. K., Misra M.: A study of carbonized lignin as an alternative to carbon black. ACS Sustainable Chemistry and Engineering, 2, 1257-1263 (2014).

https://doi.org/10.1021/sc500086v

[15] Kardashev B. K., Orlova T. S., Smirnov B. I., Wilkes T. E., Faber K. T.: Young's modulus and internal friction in porous biocarbon white pine wood precursors. Physics of the Solid State, 51, 2463-2468 (2009). https://doi.org/10.1134/s1063783409120063

[16] Xie X., Goodell B., Qian Y., Peterson M., Jellison J.: Significance of the heating rate on the physical properties of carbonized maple wood. Holzforschung, 62, 591596 (2008).

https://doi.org/10.1515/HF.2008.090
[17] Muthuraj R., Misra M., Mohanty A. K.: Injection molded sustainable biocomposites from poly(butylene succinate) bioplastic and perennial grass. ACS Sustainable Chemistry and Engineering, 3, 2767-2776 (2015). https://doi.org/10.1021/acssuschemeng.5b00646

[18] Behazin E., Misra M., Mohanty A. K.: Sustainable biocarbon from pyrolyzed perennial grasses and their effects on impact modified polypropylene biocomposites. Composites Part B: Engineering, 118, 116-124 (2017). https://doi.org/10.1016/j.compositesb.2017.03.003

[19] Major I., Pin J-M., Behazin E., Rodriguez-Uribe A., Misra M., Mohanty A.: Graphitization of miscanthus grass biocarbon enhanced by in situ generated FeCo nanoparticles. Green Chemistry, 20, 2269-2278 (2018). https://doi.org/10.1039/c7gc03457a

[20] Tripathi M., Sahu J. N., Ganesan P.: Effect of process parameters on production of biochar from biomass waste through pyrolysis: A review. Renewable and Sustainable Energy Reviews, 55, 467-481 (2016).

https://doi.org/10.1016/j.rser.2015.10.122

[21] Flauzino Neto W. P., Mariano M., da Silva I. S. V., Silvério H. A., Putaux J-L., Otaguro H., Pasquini D., Dufresne A.: Mechanical properties of natural rubber nanocomposites reinforced with high aspect ratio cellulose nanocrystals isolated from soy hulls. Carbohydrate Polymers, 153, 143-152 (2016).

https://doi.org/10.1016/j.carbpol.2016.07.073

[22] Quosai P., Anstey A., Mohanty A. K., Misra M.: Characterization of biocarbon generated by high- and lowtemperature pyrolysis of soy hulls and coffee chaff: For polymer composite applications. Royal Society Open Science, 5, 1-16 (2018).

https://doi.org/10.1098/rsos.171970

[23] Reimer C., Snowdon M. R., Vivekanandhan S., You X., Misra M., Gregori S., Mielewski D. F., Mohanty A. K.: Synthesis and characterization of novel nitrogen doped biocarbons from distillers dried grains with solubles (DDGS) for supercapacitor applications. Bioresource Technology Reports, 9, 100375/1-100375/7 (2020). https://doi.org/10.1016/j.biteb.2019.100375

[24] Lu H., Madbouly S. A., Schrader J. A., Srinivasan G., McCabe K. G., Grewell D., Kessler M. R., Graves W. R.: Biodegradation behavior of poly(lactic acid) (PLA)/ distiller's dried grains with solubles (DDGS) composites. ACS Sustainable Chemistry and Engineering, 2, 2699-2706 (2014). https://doi.org/10.1021/sc500440q

[25] Zhang Q., Khan M. U., Lin X., Cai H., Lei H.: Temperature varied biochar as a reinforcing filler for high-density polyethylene composites. Composites Part B: Engineering, 175, 107151/1-107151/7 (2019). https://doi.org/10.1016/j.compositesb.2019.107151

[26] Ogunsona E. O., Misra M., Mohanty A. K.: Sustainable biocomposites from biobased polyamide 6,10 and biocarbon from pyrolyzed miscanthus fibers. Journal of Applied Polymer Science, 134, 4421/1-4421/11 (2017). https://doi.org/10.1002/app.44221 
[27] Mohanty A. K., Vivekanandhan S., Pin J-M., Misra M.: Composites from renewable and sustainable resources: Challenges and innovations. Science, 362, 536-542 (2018). https://doi.org/10.1126/science.aat9072

[28] Peterson S. C., Chandrasekaran S. R., Sharma B. K. Birchwood biochar as partial carbon black replacement in styrene-butadiene rubber composites. Journal of Elastomers and Plastics, 48, 305-316 (2016). https://doi.org/10.1177/0095244315576241

[29] Peterson S. C., Kim S.: Reducing biochar particle size with nanosilica and its effect on rubber composite reinforcement. Journal of Polymers and the Environment, 28, 317-322 (2020). https://doi.org/10.1007/s10924-019-01604-x

[30] Xue B., Wang X., Sui J., Xu D., Zhu Y., Liu X.: A facile ball milling method to produce sustainable pyrolytic rice husk bio-filler for reinforcement of rubber mechanical property. Industrial Crops and Products, 141, 111791/1-111791/8 (2019). https://doi.org/10.1016/j.indcrop.2019.111791

[31] Bahl K., Miyoshi T., Jana S. C.: Hybrid fillers of lignin and carbon black for lowering of viscoelastic loss in rubber compounds. Polymer, 55, 3825-3835 (2014). https://doi.org/10.1016/j.polymer.2014.06.061

[32] Agrawal S. L., Mandot S. K., Mandal N., Bandyopadhyay S., Mukhopadhyay R., Deuri A. S., Mallik R., Bhowmick A. K.: Effect of corn powder as filler in radial passenger tyre tread compound. Journal of Materials Science, 41, 5657-5665 (2006).

https://doi.org/10.1007/s10853-006-0264-8

[33] Picard M., Thakur S., Misra M., Mielewski D. F., Mohanty A. K.: Biocarbon from peanut hulls and their green composites with biobased poly(trimethylene terephthalate) (PTT). Scientific Reports, 10, 1-14 (2020). https://doi.org/10.1038/s41598-020-59582-3

[34] Tadele D., Roy P., Defersha F., Misra M., Mohanty A. K.: A comparative life-cycle assessment of talc- and biochar-reinforced composites for lightweight automotive parts. Clean Technologies and Environmental Policy, 22, 639-649 (2020).

https://doi.org/10.1007/s10098-019-01807-9

[35] Dannenberg E. M.: Filler choices in the rubber industry. Rubber Chemistry and Technology, 55, 860-880 (1982). https://doi.org/10.5254/1.3535905

[36] Kruželák J., Sýkora R., Hudec I.: Sulphur and peroxide vulcanisation of rubber compounds - Overview. Chemical Papers, 70, 1533-1555 (2016). https://doi.org/10.1515/chempap-2016-0093

[37] Ma Z., Wang J., Yang Y., Zhang Y., Zhao C., Yu Y., Wang S.: Comparison of the thermal degradation behaviors and kinetics of palm oil waste under nitrogen and air atmosphere in TGA-FTIR with a complementary use of model-free and model-fitting approaches. Journal of Analytical and Applied Pyrolysis, 134, 12-24 (2018). https://doi.org/10.1016/j.jaap.2018.04.002
[38] Sarkar P., Bhowmick A. K.: Terpene based sustainable elastomer for low rolling resistance and improved wet grip application: Synthesis, characterization and properties of poly(styrene-co-myrcene). ACS Sustainable Chemistry and Engineering, 4, 5462-5474 (2016). https://doi.org/10.1021/acssuschemeng.6b01038

[39] Xing W., Tang M., Wu J., Huang G., Li H., Lei Z., Fu X., Li H.: Multifunctional properties of graphene/rubber nanocomposites fabricated by a modified latex compounding method. Composites Science and Technology, 99, 67-74 (2014). https://doi.org/10.1016/j.compscitech.2014.05.011

[40] Mathew N. M., Bhowmick A. K., De S. K.: Network changes in natural rubber vulcanizates under compression. Journal of Applied Polymer Science, 27, 18271832 (1982). https://doi.org/10.1002/app.1982.070270538

[41] Wang T., Rodriguez-Uribe A., Misra M., Mohanty A. K.: Sustainable carbonaceous biofiller from miscanthus: Size reduction, characterization, and potential bio-composites applications. BioResources, 13, 3720-3739 (2018).

https://doi.org/10.15376/biores.13.2.3720-3739

[42] Parkinson B. D.: The reinforcement of rubber by carbon black. Journal of Applied Physics, 2, 273-280 (1951). https://doi.org/10.1088/0508-3443/2/10/301

[43] Toth P., Vikström T., Molinder R., Wiinikka H.: Structure of carbon black continuously produced from biomass pyrolysis oil. Green Chemistry, 20, 3981-3992 (2018).

https://doi.org/10.1039/c8gc01539b

[44] Bhattacharya M., Bhowmick A. K.: Synergy in carbon black-filled natural rubber nanocomposites. Part I: Mechanical, dynamic mechanical properties, and morphology. Journal of Materials Science, 45, 6126-6138 (2010). https://doi.org/10.1007/s10853-010-4699-6

[45] Kraus G.: Reinforcement of elastomers by carbon black. Macromolecular Materials and Engineering, 60, 215248 (1977). https://doi.org/10.1002/apmc.1977.050600109

[46] Ogunsona E., Misra M., Mohanty A. K.: Impact of interfacial adhesion on the microstructure and property variations of biocarbons reinforced nylon 6 biocomposites. Composites Part A: Applied Science and Manufacturing, 98, 32-44 (2017).

https://doi.org/10.1016/j.compositesa.2017.03.011

[47] Al-Hartomy O. A., Al-Ghamdi A. A., Farha S., Al Said S. F., A., Dishovsky N., Mihaylov M., Malinova P.: Comparative study of the dynamic properties of natural rubber based composites, containing carbon-silica dual phase fillers obtained by different methods. Journal of Chemical Technology and Metallurgy, 50, 567-576 (2015). 
[48] Galimberti M., Cipolletti V., Cioppa S., Lostritto A., Conzatti L.: Reduction of filler networking in silica based elastomeric nanocomposites with exfoliated organomontmorillonite. Applied Clay Science, 135, 168-175 (2017).

https://doi.org/10.1016/j.clay.2016.09.017

[49] Rattanasom N., Prasertsri S.: Relationship among mechanical properties, heat ageing resistance, cut growth behaviour and morphology in natural rubber: Partial replacement of clay with various types of carbon black at similar hardness level. Polymer Testing, 28, 270-276 (2009).

https://doi.org/10.1016/j.polymertesting.2008.12.010

[50] Grimm A., Skoglund N., Boström D., Öhman M.: Bed agglomeration characteristics in fluidized quartz bed combustion of phosphorus-rich biomass fuels. Energy and Fuels, 25, 937-947 (2011).

https://doi.org/10.1021/ef101451e
[51] Thulasiraman R., Kathirvelan C., Purushothaman M. R.: Chemical composition and in vitro dry matter digestibility of dried distillers grain solubles. International Journal of Science, Environment and Technology, 4, 11771180 (2015).

[52] Kaewsakul W.: Silica-reinforced natural rubber for low rolling resistance, energy-saving tires: Aspects of mixing, formulation and compatibilization. $\mathrm{PhD}$ thesis, University of Twente (2013). https://doi.org/10.3990/1.9789036535151

[53] Matos C. F., Galembeck F., Zarbin A. J. G.: Multifunctional and environmentally friendly nanocomposites between natural rubber and graphene or graphene oxide. Carbon, 78, 469-479 (2014). https://doi.org/10.1016/j.carbon.2014.07.028

[54] Wu J., Li K., Pan X., Liao S., You J., Zhu K., Wang Z.: Preparation and physical properties of porous starch/ natural rubber composites. Starch, 70, 1-8 (2018). https://doi.org/10.1002/star.201700296 